\title{
El "Informe Sobre Ciegos" o el Optimismo de la Voluntad
}

Desde su aparición en 1961, la novela Sobre béroes y tumbas de Er. nesto Sábato, ha desatado una serie de interpretaciones y críticas, todas ellas acertadas en grado mayor o menor como siempre sucede con una novela importante. Sin embargo, si lo mucho que se ha escrito sobre la obra en general revela un alto grado de consistencia y coincidencia de opinión, es imposible sostener lo mismo respecto a una parte esencial de la novela: el "Informe sobre ciegos". Este capítulo -uno de los cuatro que integran Sobre béroes y tumbas- ha dado lugar a interpretaciones diferentes y no existe, que yo sepa, un estudio específicamente dedicado a él. En su libro sobre Sábato la profesora Dellepiane nos proporciona una valiosa discusión del clima edípico-sofocleano que se extiende por todo el episodio del descenso. Pero sus conclusiones basadas en la novela entera son imprecisas e incompletas. Según ella, el personaje central del "Informe", Fernando Vidal Olmos, representa sólo una faz del hombre, "la desagradable, la demoníaca, la que debe perecer."' Además sostiene que este personaje "resulta al final un enigma, como también lo es todo el 'Informe'." 2 Aunque la personalidad de Fernando - comentada por Bruno y contrastada con la de Martín- se describe con más detalles en la novela, no se ensancha realmente. Su fisonomía moral e intelectual queda bien definida en el "Informe", y considerada sólo desde este punto de vista, resulta menos ambigua y más positiva que con ayuda de las aclaraciones y los episodios adicionales en los otros cuatro capitulos de Sobre béroes y tumbas.

La función del "Informe" dentro de la novela es bastante obvia: es la transcipción de la gran pesadilla de Fernando Vidal, la cual ex-

1 Ángela B. Dellepiane, Emesto Sábato: El bombre y su obra (New York: Las Américas Publishing Co.; 1968), p. 270.

2 P. 206. 
presa, según las palabras del mismo autor, "lo más importante de su condición y existencia". ${ }^{3}$ Relatado en primera persona, el "Informe" permite al lector llegar a un profundo conocimiento del protagonista; es decir, descubrir no sólo su comportamiento exterior y su modo de pensar, sino también lo conduce a penetrar en su conciencia y, más importante aún, en su inconciencia. Por eso hay que insistir que sin el "Informe" la novela resultaría trunca e incompleta.

Pero el "Informe" además de ser un capítulo importante a la manera del "Teatro mágico" en El lobo de la estepa de Hermann Hesse, constituye por sí mismo una novela autónoma por su independencia expresiva y significativa del resto de la novela. Esto lo ha reconocido la crítica y el mismo Sábato al permitir su publicación en forma de un libro sin ningún aparato introductorio que explique su relación con el resto de Sobre béroes y tumbas.4 De este modo el lector puede llegar a sus propias conclusiones sobre Fernando y su investigación.

Sábato adopta una actitud terriblemente pesimista ante la vida a través de Pablo Castel, protagonista de su primera novela, El thinel. En Sobre béroes y humbas, en cambio, dos de los personajes importantes, Bruno y Martín, sobreviven una crisis nihilista, representando de este modo una nueva cosmovisión, "algo así como una absurda metafísica de la esperanza." Al nihilismo Sábato opone una terca esperanza que sobrevive a causa y a pesar de todos los contratiempos que tiene que sufrir el hombre. Peto los dos personajes que encarnan esta idea se destiñen en comparación con Fernando Vidal, el ser más viril y vital de la creación sabateana. También él reconoce el sentido trágico de la vida, pero niega al verdadero pesimismo con el vigor de su lucha.

Las tres alusiones a Darwin y sus teorías sobre la evolución de las especies que aparecen en el "Informe" (pp. 23, 38, 40) ${ }^{6}$ como elemento incidental son como una clave indirecta a su interpretación. Con los descubrimientos de Darwin se puso en duda la creencia en la superioridad del hombre sobre las otras formas de vida animal y se destruyó la noción de la perfectibilidad gradual de los románticos panteístas, ya que cada especie se consideraba perfecta dentro de su propio modo de ser. En el orden filosófico este concepto de la petfección biológica negó al hombre

3 Ernesto Sábato, El escritor y sus fantasmas (Buenos Aires: Aguilar, 1963), p. 19.

4 Informe sobre ciegos (Buenos Aires: Centro Editor de América Latina, 1968)

5 El escritor y sus fantasmas, p. 19.

6 Informe sobre ciegos (Buenos Aires, 1968). Todas las citas se hacen por esta edición y se indicarán en el texto por página o páginas. 
el anhelo del absoluto, reservándole el mismo fin que al animal más insignificante.

Ahora bien, Fernando vive la crisis desencadenada por este concepto materialista de la vida, pero como gran rebelde metafísico no busca la consolación, sino se enfrenta plenamente con el problema, imponiéndose una búsqueda que lo llevará a una revelación terrible sobre el destino del hombre. En su peregrinaje Fernando descubrirá sólo la maldad y la muerte. Lo que hay más allá no lo sabrá nunca, pero su búsqueda es una verdadera lucha heroica: "de pronto me sentí una especie de héroe, de héroe al revés, héroe negro y repugnante, pero héroe. Una especie de Sigfrido de las tinieblas, avanzando en la oscuridad y la fetidez con mi negro pabellón restallante. . ¿Pero avanzando hacia qué? Eso es lo que no alcanzo a discernir y que aún ahora, en estos momentos que preceden mi muerte, tampoco llego a comprender" (p. 112). Aunque Fernando se llama a sí mismo un "héroe al revés", eso no significa que él sea un héroe negativo o un nihilista. Se salva por la voluntad de lucha y el anhelo de expiación que se despierta en él durante sus andanzas por el universo subterráneo.

Fernando representa, sin duda, uno de los grandes rebeldes de toda la literatura hispanoamericana, a la altura de un Stavroguin o un Ivan Karamazoff. Su rebelión, como la de todos los grandes rebeldes literarios e históricos, es una protesta contra la condición de la vida misma -el mal inherente a la sociedad y la naturaleza humana- y una denuncia contra Dios: "la idea de que estuviéramos gobernados por un Dios omnipotente, omnisciente y bondadoso me parecía tan contradictoria que ni siquiera creía que se pudiese tomar en serio" (p. 13). A continuación Fernando elabora una serie de teorías sobre la existencia y la ineficacia de Dios. Si Dios existe debe ser un canalla, un dormido, un loco, tan débil como el hombre, quien en su lucha con la materia a veces "logra ser Goya, pero generalmente es un desastre" (pp. 13-14). Finalmente, en sus cavilaciones sobre Dios que permite el triunfo del mal en el mundo, Fernando llega a la conclusión que Dios fue derrotado antes de la Historia "y sigue gobernando el Príncipe de las Tinieblas" (p. 15) - los ciegos. Así, la protesta contra la maldad se expresa en una rebelión exagerada. Dios aparece humanizado (un ser desastroso) y degradado (un canalla, un loco). Al mismo tiempo Fernando se convierte en su rival. Desesperado de la justicia de Dios y contando sólo con sus propios esfuerzos, se lanzará a la investigación del mal. Como Empidócleo quien se tiró en el cráter del Etna para encontrar la verdad en las entrañas de la tierra, 
Fernando se propone descubrirla en su peregrinaje por el mundo subterráneo de los ciegos.

El tema de la rebelión contra Dios ha sido tratado por muchos de los más grandes escritores de la literatura mundial: Esquilo, Dante, Milton, Goethe, Baudelaire. Peto la vehemencia de la blasfemia expresada por Fernando cuando retrata a un Dios-canalla, a un Dios-pobre-diablo, etc., está superada sólo por Lautréamont en Les Chants de Maldoror, donde se le acusa a Dios de haber pecado y cometido un crimen.

Fernando también se rebela contra los sentimientos convencionales y los tabúes respetados por la sociedad. Es el seductor de Norma Pugliese, hija de un antiguo miembro del partido Socialista, y educada por su padre "en las normas que Juan B. Justo impuso desde el comienzo: la Verdad, la Ciencia, el Cooperativismo, la Lucha contra el Tabaco, el Antialcoholismo" (p. 44). Este episodio transparenta la actitud sarcástica, amoral y antiburguesa de Fernando. Al relatar su fácil conquista de la muchacha, critica ciertos conceptos morales - los que se escriben con mayúsculay las principales instituciones de la sociedad moderna. Otros episodios del "Informe" - la discusión que Fernando tiene con la señorita hom. bruna, Inés González Iturrat, sus visitas a la casa de la señora Etcheparaborda, los incidentes relacionados con su paso por Montevideo- tienen el mismo propósito satírico y burlesco. Sin embargo, la crítica que Fer. nando hace a la sociedad es aún más virulenta cuando denuncia la hipo. cresía y la inocencia y la bonhomía falsas. Para todos esos canallas Fer. nando propone un sistema de castigo: "A cada uno la mierda que le corresponda, o nada" (p. 48). En estos episodios prevalece un marcado sentido de comicidad muy moderno que evoca el humor de un James Joyce o de un Picasso y anterior a ellos, de un Jonathan Swift. Es ef humor negro que linda con lo grotesco, y si provoca la risa no parte de ella.

Como terrorista de la moral burguesa, Fernando también se acusa a sí mismo de ser un "canalla". Pero se considera por lo menos más honesto que la mayoría de los hombres y puede justificar sus engaños: "Son y eran engaños tácticos, circunstanciales, transitorios, en favor de una verdad a fondo, de una despiadada investigación. Soy un investigador del Mal" (p. 46). Se ve que la maldad de Fernando es exigida por su aventura irracional - "siempre pensé que no se puede luchar durante años contra un poderoso enemigo sin terminar por parecerse a él" (p. 70). Se somete voluntariamente a este régimen para así poder hallar una manera de librarse del mal. Obviamente, Fernando está atrapado dentro 
de un círculo vicioso, pero su dilema de ser a la vez el perseguidor de la Secta y el perseguido por ella se resuelve sólo al final con su expiación.

Fernando, como todo rebelde genuino, tiene que romper con las for. mas habituales de la vida. Para él no puede existir ni familia, ni amigo, ni amada. Su soledad absoluta es el precio de su libertad. Que su aislamiento de los demás hombres es extremo y voluntario demuestran las palabras que preceden su confesión de la falta de afecto en su vida: "nadie en su sano juicio podría sostener que el objetivo de estos papeles ["informe"] sea el de despertar simpatía hacia mi persona. He aquí, por ejemplo, uno de los hechos desagradables que como muestra de mi sinceridad voy a confesar: no tengo ni nunca he tenido amigos. . jamás he sentido afecto por nadie, ni creo que nadie lo haya sentido por mi" (p. 21).

La condición de solitario explica en gran parte las acciones violentas y sádicas de Fernando. Un análisis de algunas de ellas revela que la crueldad es también un régimen que él se ha impuesto por su propia voluntad. ¿Por qué en su niñez torturaba los pájaros, pinchándoles los ojos con un clavo? Creo que la explicación se da en un segundo ejemplo análogo: Desde chico Fernando repetía una escena cruel con un hormi. guero. Mataba las hormigas con un martillo, luego les echaba agua con una manguera y, finalmente, con una pala destruía sus cuevas. El mismo Fernando atribuye este acto de crueldad gratuito ${ }^{7}$ a su preocupación con el problema de la maldad (p. 13). Así, las dos ocasiones, cuando Fer. nando pincha los ojos de los pájaros y cuando destruye el hormiguero, son para él nada más que experimentos con los cuales trata de comprobar su hipótesis sobre el mal. El experimento de su madurez será la investigación de la secta de los ciegos, decretada también por su propia voluntad ( . 127). Además, como ya se ha visto esta clase de experimentación exime a Fernando de toda tradición y convención, preparando así el camino de su investigación.

Cabe agregar que la violencia colorea todo el "Informe", tanto la parte que se ciñe estrictamente a la descripción del descenso al mundo de los ciegos, como las tres subnovelas relatadas por Fernando: la de Castel (paráfrasis de $E l$ tainel), la de la modelo ciega, y la de los muertos en el ascensor. Por otra parte, Sábato desarrolla en el "Informe" toda una estética de la violencia y de la repulsión a base de un vocabulario

7 "La teoría del acto gratuito es la culminación de la demanda por la libertad absoluta." Albert Camus, The Rebel, trad. Anthony Bower (New York: Vintage Books, 1956), p. 93. Ésta y las demás traducciones son mías. 
sugestivo de agresividad y repugnancia, ${ }^{8}$ y especialmente a base de numerosas imágenes zoológicas.

En las 130 páginas que componen el "Informe" se mencionan cua. renta nombres de animales diferentes, de los cuales la mayoría está in. vocada más de una vez (hasta trece veces como en el caso de 'pájaro'). Agregando a este número de animales históricos y prehistóricos, los mitológicos (minotauro, centauro, medusa, etc.) y otros designados con palabras como 'bichos', 'monstruos', 'fieras', etc., se puede encontrar un promedio de una referencia al mundo animal por cada página. Los animales que aparecen en el "Informe" raras veces forman parte de frases hechas (ej.: 'cerebro de mosca') y nunca sirven de elemento decorativo. Interesan principalmente por su capacidad de sugerir agresión y repul. sión. Así, entre los más amenazantes se encuentra el pájaro ${ }^{9}$ que hiere con el pico, el vampiro que chupa la sangre de su víctima, y el pulpo que estrangula con su abrazo. Otros, como la serpiente y el tiburón también son agresivos y además símbolos tradicionales del mal. La mayoría de los animales pertenece a la categoría de los repugnantes: ratas, murciélagos: toda clase de reptiles, batracios, cucarachas, tarántulas, gusanos, etc. El pez como también un gran número de los animales mencionados arriba desem. peñan un papel en los importantes episodios de metamorfosis.

Hay dos clases de metamorfosis en el "Informe", la de Celestino Iglesias y la de Fernando Vidal. Las dos están relacionadas con la investigación del mal, pero sólo la del protagonista es transcendente para la obra. La transformación de Iglesias después de su accidente de ceguera es esencialmente la transformación paulatina de un ser bondadoso y humano en algo menos, en algo monstruoso y maléfico: "empezó a cambiar la mentalidad de Iglesias; aunque más que la mentalidad ( $y$ menos) habría que decir su 'raza' o 'condición zoológica'" (p. 28). Aunque Igle. sias no cambia en su aspecto exterior, Fernando siente en su presencia una repulsión como ante un murciélago o reptil. La animalización de Iglesias como la de todos los ciegos sirve para reforzar su asociación con el mal. Por contraste, la metamorfosis de Fernando tiene que ver con su investigación o exploración que se desenvuelve en dos direcciones: como

8 Son tantos los ejemplos que no me parece indicado citarlos aquí.

- El retrato físico de Fernando que destaca sus rasgos crueles y agresivos se da en otro capítulo de la novela: "Sus rasgos eran duros y la cara parecía ta. llada con hacha. Aquel hombre no sólo era fuerte, sino que estaba dotado de una tenebrosa belleza... Sus manos descarnadas y nerviosas parecian tener cierto pa. rentesco con las garras de un águila... Todo lo de aquel individuo tenía algo de un ave de rapiña." Sobre béroes y tumbas (Buenos Aires: Editorial Sudame. ricana, 1968), p. 239. 
un descenso al "propio y tenebroso" mundo del yo, y como una marcha atrás en el tiempo hasta el origen del dilema del hombre.

En terminologia jungiana, el descenso al yo significa el reconocimiento del arquetipo de la sombra que, a su vez, es sólo posible cuando se reconocen los aspectos oscuros y bajos de la personalidad como presentes y reales. Este reconocimiento de la sombra, según Jung, exige un gran esfuerzo moral y resulta en una experiencia tremenda porque le pone al hombre cara a cara con el mal absoluto: ". . estái dentro de los límites que un hombre reconozca el mal relativo de su naturaleza, pero es una experiencia rara y tremenda mirar la faz del mal absoluto". ${ }^{10}$ Fernando, que es tan despiadado consigo mismo como con el resto de la humanidad, tiene la intrepidez y el coraje del rebelde para someterse voluntariamente a este experimento.

Una prefiguración de las metamorfosis al final del libro ocurre en un sueño que Fernando ha tenido repetidas veces desde su juventud. En esta pesadilla sufre la pérdida de su identidad en una extraña transformación que, sin ser física, es sentida por él en el cuerpo y en un plano zoológico: "grandes regiones de mi espíritu empiezan a hincharse (a veces hasta siento la presión en mi cuerpo, en mi cabeza sobre todo), avanzan como silenciosos pseudopodios, ciegos y sigilosos, hacia otras regiones de la raza y finalmente, hacia oscuras y antiguas regiones zoológicas" (p. 20). La transformación en este sueño surrealista se desarrolla en dos niveles, el físico y el espiritual, y sugiere que Fernando, quien aspira a cruzar los límites que separan al hombre del resto del universo, iniciará el retorno a un nivel de vida primario, a un tiempo cuando la moralidad y el pro. blema de la inmortalidad todavía no tenían ninguna significancia para el hombre.

En la última etapa de su peregrinación por el submundo de los ciegos, Fernando se encuentra con dos figuras representativas del arquetipo de la madre. Según la clasificación de Jung, este arquetipo aparece bajo tres aspectos fundamentales: la bondad, la pasión erótica, y la oscuridad. ${ }^{11}$ Como veremos más adelante, en el mundo subterráneo sólo existen la madre de la muerte y la madre de la maldad; la madre comprensiva y buena no tiene cabida en él.

Cuando Fernando llega a "una comarca donde parecía celebrarse una sola y petrificada Ceremonia de la muerte" (p. 122), ve una estatua de una deidad desnuda en cuyo vientre fulgura un ojo fosforescente que

10 The Collected Works of C. G. Jung (New York, 1959), citado en The Modern Tradition, editado por Richard Ellmann y Charles Feidelson (New York: Oxford University Press, 1965), pp. 653-654.

11 Pp. 657-658. 
lo llama. Para ascender a este ojo útero Fernando tiene que desandar el camino de la especie. Se convierte en pez, experimenta la aniquilación del tiempo y del espacio, y ve pasar ante su conciencia en imágenes calidoscópicas escenas de su vida, la mayoría de ellas horrorosas y sugestivas de su culpabilidad y su terror ante el castigo. Luego pierde la conciencia, entregándose a la sensación de estar hundido en "aguas cálidas, gelatinosas y fosforescentes" (p. 125). Esta deidad nocturna que absorbe a Fernando "con una incontenible fuerza de succión" (p. 125), es la madre terrible, símbolo del destino ineludible del hombre. Más tarde cuando el protagonista reflexiona sobre esta aventura la considera como una profecía de su muerte: "Y así en aquel viaje supe, como Edipo lo supo de los labios de Tiresias, cuál era el fatal fin que me estaba reservado" (p. 127). Sin embargo, es importante tener en cuenta que Fernando busca y hasta cierto punto determina su destino: "esta muerte me espera en cierto modo por mi propia voluntad" (p. 131).

La segunda aparición arquetípica de la madre es la Ciega lujuriosa que despierta en Fernando la pasión erótica. Al unirse con ella en "la más tenebrosa de las cópulas" (p. 127), Fernando vuelve a perder la noción temporal y espacial, y nuevamente recorre las especies: "fui hombre y pez, fui batracio, fui un gran pájaro prehistórico" (p. 129). A continuación como pareja de la Ciega - convertida ahora en ídolo de piel negra con ojos color violeta- Fernando se transforma en centauto, unicornio, serpiente, pez-espada, pulpo, vampiro, sátiro, gigante, tarántula enloquecida, lujuriosa salamandra, mago, perro hambriento, minotauro, pájaro de fuego, hombre-serpiente, rata fálica, nave con mástiles de carne, campanario lúbrico (pp. 129-130). Así Fernando se enfrenta con su crimen -el incesto ${ }^{12}$ - y su expiación y purificación - la cópula monstruosa con la Ciega termina con la destrucción del mundo por un incendio. La grotesca unión con la Ciega, como Fernando se da cuenta, obedece a "un oscuro pero tenaz llamamiento de su propio ser" (p. 127), y representa, a un tiempo, el crimen y el castigo. Las horribles transformaciones que Fernando sufre durante la cópula son su castigo como en Les Cbants de Maldoror donde el héroe, después de su cópula con el tiburón, es casti. gado con la transformación de sus extremidades en aletas de un pescado. De este modo Fernando se entera que el crimen y el castigo son los dos lados de una misma cosa, debidos ambos a su propia voluntad: "Y tam-

12 No estoy de acuerdo con la interpretación de la profesora Dellepiane de que la Ciega "no es otra que Alejandra" (p. 271). En el "Informe" no sabemos nunca que Fernando tiene una hija. En mi opinión, la Ciega es la encarnación de la madre. La madre es el más universal símbolo del incesto, ya que todo hombre necesariamente tiene una madre, pero no siempre una hija. 
bién pienso si era mi oscura e indeliberada voluntad la que pacièntemente había suscitado aquella encarnación [de la madre] que la Ciega perversamente me facilitaba o si la Ciega y todo aquel Universo de Ciegos, al que ella pertenecía era al revés, una formidable organización a mi servicio, para mi voluptuosidad, mi pasión y finalmente, mi castigo" (p. 128).

La metamorfosis de Fernando tiene una significación distinta y más positiva de la famosa pesadilla descrita por Franz Kafka. La animalización de Gregor Samsa es un símbolo de la barrera inviolable que existe entre él y el resto de la sociedad. En cambio, la metamorfosis de Fernando representa un desandar del tiempo por el hombre moderno, angustiado y anhelante del infinito para encontratse con su destino y descubrir en un pasado misterioso y lejano un crimen que lo ha alienado permanentemente de Dios.

La búsqueda de Fernando es un afán de reconstruir —en el sentido surrealista- al hombre, dividido por una civilización abstracta, a partir de la absoluta libertad de lo inconsciente. Por eso rechaza con tanta vehemencia la idea de la casualidad ${ }^{13}$ y se impone la aventura irracional. Su propia maldad está determinada por un deseo de merecer su destino. Lo que importa aquí no son los hechos sino la esencia. Fernando escoge ló peor porque no le es dada otra elección. Por lo tanto, su vida se define como un largo peregrinaje hacia lo inevitable: "La astucia, el deseo de vivir, la desesperación, me han hecho imaginar mil fugas, mil formas de escapar a la fatalidad. Pero, ¿cómo nadie puede escapar a su propia fatalidad?" (p. 132). Lo que empezó como odium fati parece terminar como amor fati. La interrogación final implica que el destino y la voluntad son las dos caras de una misma moneda. Ya que Fernando no puede escapar a la fatalidad, la suscitará con su propia voluntad; ya que le es imposible aceptar la vida tal como es, creará su vida de esta imposibilidad —su vida será una rigurosa prueba reservada para él solo.

TAMARA Holzapfel

University of New Mexico

\footnotetext{
13 " $Y$ cuando uno se propone enérgica y sistemáticamente un fin que esté dentro de las posibilidades del mundo determinado, cuando se movilizan no sólo las fuerzas conscientes de nuestra personalidad sino las más poderosas de nuestra subconsciencia, se termina por crear un campo de fuerzas telepáticas en torno de uno que impone a otros seres nuestra voluntad, y hasta se producen episodios que en apariencia son casuales pero que en rigor están determinados por esa invisible potencia de nuestro espíritu." Informe, p. 25.
} 
